\title{
POTENTIAL PRODUCTION OF ELECTRICAL ENERGY FROM FOREST BIOMASS IN THE NORTH OF SPAIN: CANTABRIA
}

\author{
S. Pérez, C. J. Renedo, D. Silió, A. Ortiz and M. Mañana \\ Dpto. Ingeniería Eléctrica y Energética de la Universidad de Cantabria \\ E.T.S. de Ingenieros Industriales y de Telecomunicaciones \\ Av Los Castros s/n 39005 Santander Cantabria \\ Phone number:+0034 9422013 76, e-mail: renedoc@unican.es
}

\begin{abstract}
In this work, the authors analyze productive, power, environmental and economic aspects of the forest biomass in the north of Spain. All these points will determine the future development of this power resource, making special reference to the case of the province of Cantabria.
\end{abstract}

\section{Key words}

Biomass, forest remainders, combustion, electrical energy.

\section{Introduction}

Biomass is all alive matter that has existed in the Earth. But from the power point of view, it is all organic matter from animal or vegetable origin, including the materials resulting from its transformation, which are susceptible to be used for power production.

The primary origin of the biomass is in the energy of the Sun, which is used by plants for its growth, by means of the photosynthesis. However, there are not only biomass of natural origin, but they also exist biomass coming from cattle remainders, from other human activities, such as the remainders of wood industry, or even like part of the urban solid remainders; in figure 1 the different types of biomass are observed.
The forest biomass consists of the remainders of the forest maintenance, mainly firewoods, branches and scrubs.

Another forest biomass is the one that results from sawmills, from furniture manufacturing, or paper industry.

Historically, until the industrial revolution, the biomass combustion has been the power resource more used by the man for light and heating production, as much domestic as industrial. The development of this power source was based on its availability in the forests.

Currently, the main power sources used by the man are the natural gas and those derived from the petroleum, although the energy obtained from biomass is still used, specially in the developing countries. Moreover, the world climate change has caused great interest for this type of energy in the developed countries.

Due to the different types of biomass, there are diverse power applications, between which are the direct use for combustion or the production of different fuels such as vegetal coal, biological oil or biogas. These are used for thermal and electrical production, or even like fuel for vehicles.

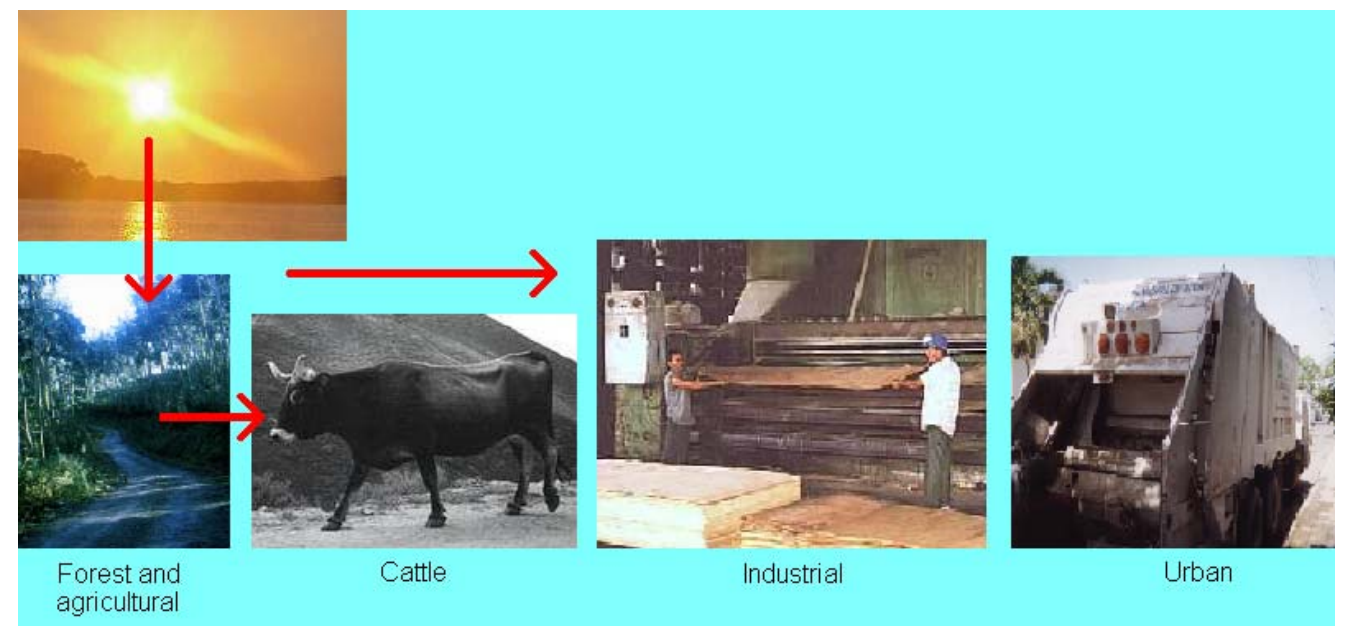

Fig 1.- Different types of biomass 
In the 25 countries of the European Union the consumption of biomass and wastes has increased from 42.6 MTep in 1991 to $61.6 \mathrm{MTep}$ in 2002. The consumption in Spain, whose evolution is shown in figure 2, increased from 3.8 to 4.1 MTep in the same period [1], which represents $6.77 \%$ of the total in 2002 .

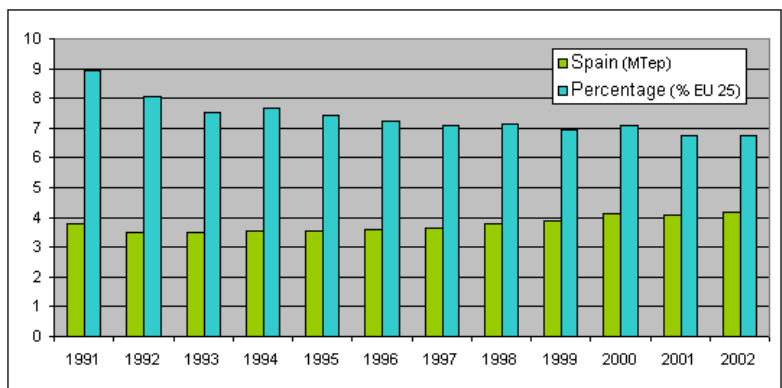

Fig 2.- Consumption of biomass and wastes in Spain between 1992 and 2002

In the EU, France is the main producer, around 8.48 MTep, followed by Germany, Finland and Sweden. However, considering the ratio of production by inhabitant, the greatest producer is Finland, with 1.23 $\mathrm{Tep} / \mathrm{hab}$, followed of Sweden, with $0.88 \mathrm{Tep} / \mathrm{hab}$. In Spain this ratio reaches only $0.1 \mathrm{Tep} / \mathrm{hab}$.

In the EU the $85 \%$ of the energy produced from biomass have purely thermal aims, while the $15 \%$ is used for the electrical energy production. In Spain the electrical production from biomass only represents $6 \%$ of this energy source.

Between the Spanish biomass plants for electrical production, the biggest one of Sanguesa, Navarra, which has a production of $200,000 \mathrm{MWh}$ per year. The technology that they use is direct combustion of the biomass, being the gasification process in phase of development.

The key aspect that will contribute to the development of the biomass use, as a power resource, is the environmental one. The activity of the man is causing a climate change in the Earth, and one of the main reasons is the emission of greenhouse gases, fundamentally $\mathrm{CO}_{2}$, $\mathrm{CH}_{4}$ and the $\mathrm{NO}_{\mathrm{x}}$, being the $\mathrm{CO}_{2}$ the one that has the greatest contribution, $80 \%$.

A social awareness in favor of the reduction of the emission of these gases exists, which has forced the politicians to make laws that protects the atmosphere from these gases.

In the conference celebrated in Kyoto in 1997 the following commitments were established:

- The countries of the OECD will reduce their emissions in 2010 a $5.2 \%$ with respect to the corresponding ones of 1990 .

- The whole EU will reduce their emissions to $92 \%$ of the existing in that moment.
- Spain could increase a $15 \%$ its emissions, on the basis of a greater reduction of other countries.

The results in the middle of the evaluation period are highly disappointed. The EU has increased their emissions 6\%, and Spain 30\%, which seems to indicate that the commitments are very far from being fulfilled, and they will remain in a mere declaration of intentions.

On the other hand, USA also have increased their emissions, at the moment their efforts focus on the buy of emission rights of other countries.

All this will foment policies that promote, through public support, the research, development and application of technologies that involve renewable power sources, between which the biomass can play an important role, since its potential is superior to the one of other alternatives.

In the article, the different aspects that influence the use of the forest wastes like power source are analyzed, specially in the electrical energy transformation, focusing the analysis in the case of the North Coast of Spain.

\section{Forest biomass in the North coast of Spain}

In the North Coast of Spain, due to its climate, exists one of the greatest sources of forest biomass of Spain, that is represented by multitude of species, between which are, birches, brown, hazels, oaks...

However, from the point of view of the wood industry two species predominate, in the coastal zone Eucalyptus Globulus (EG), and in the interior zones Pino Radiata (PR).

The current tendency is the substitution of the PR by the Eucalyptus Nitens (EN), since the development of this species is faster, and this species of eucalyptus is more resistant to the cold than the EG, which makes it suitable to be planted in interior areas.

The plantations of fast-growing in the north of Spain surpass the 300,000 Has, which justifies a viability study of the use of wood industry wastes like power source.

Because the eucalyptus is the most representative tree in the North Coast of Spain, and knowing that the type over which exists greater experience in the zone is the EG, the rest of the article will focus on it, figure 3 .

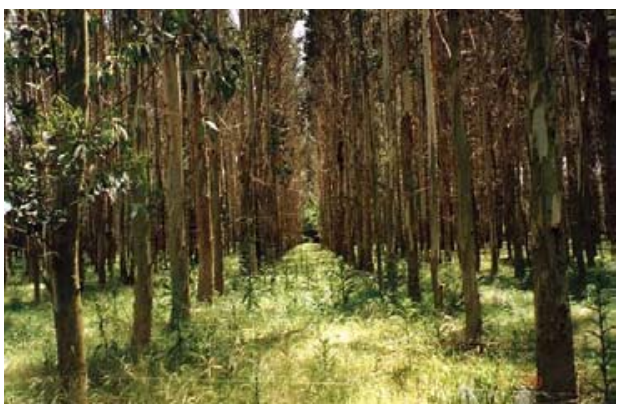

Fig 3.- Eucalyptus forest 
TABLE I.- Characteristic averages of a EG plantation

\begin{tabular}{|l|l|l|l|l|l|l|l|}
\cline { 2 - 8 } \multicolumn{1}{c|}{} & Slope $(\%)$ & $\begin{array}{l}\text { Height } \\
(\mathrm{m})\end{array}$ & $\begin{array}{l}\text { Density } \\
(\text { foot/ha })\end{array}$ & $\begin{array}{l}\mathrm{G} \\
\left(\mathrm{m}^{2} / \mathrm{ha}\right)\end{array}$ & $\begin{array}{l}\mathrm{d}_{\mathrm{g}} \\
(\mathrm{cm})\end{array}$ & $\begin{array}{l}\mathrm{H}_{\mathrm{m}} \\
(\mathrm{m})\end{array}$ & $\begin{array}{l}\mathrm{H}_{0} \\
(\mathrm{~m})\end{array}$ \\
\hline Average & 11,3 & 262 & 1.725 & 34,3 & 16,4 & 22.07 & 26,79 \\
\hline Tipical desviation & 10,3 & 89 & 583 & 9,4 & 3,9 & 3.83 & 4,51 \\
\hline
\end{tabular}

G basimetrical area $\mathrm{d}_{\mathrm{g}}$ diameter $\mathrm{H}_{\mathrm{m}}$ useful height $\mathrm{H}_{0}$ overall height

The place in which the study has been made is the province of Cantabria, however the results can be extrapolated to any region of the North of Spain, or to any other place with similar climatic and terrain characteristics.

An aspect very important to stand out is that, in spite of being in a land near the coast, this area is very mountainous. Some of the Cantabrian mountains are over 2,000 meters height, at distances of $50 \mathrm{~km}$ of the coast, figure 4.

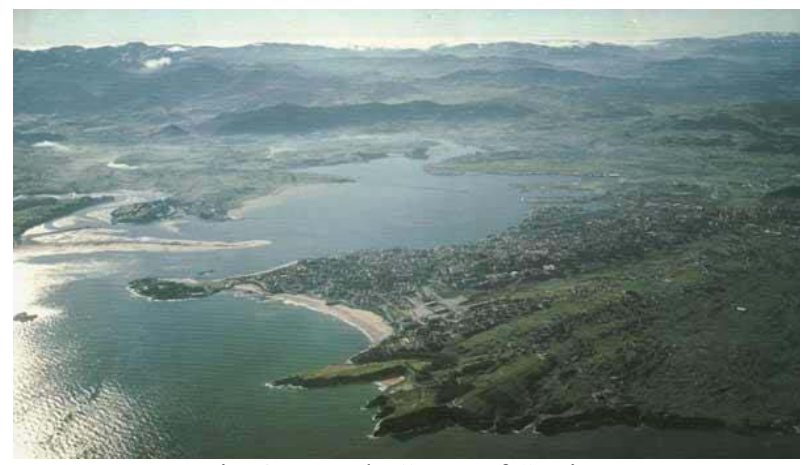

Fig 4.- North Coast of Spain

On the other hand, the presence of these mountains near the coast, causes that the climate is specially rainy, since they form a barrier for the clouds that try to cross them.

\section{Quantification of forest biomass in plantations of Eucalyptus Globulus}

In this section, mathematical methods and models to quantify the biomass in a plantation are described.

In Galicia, it has been made studies in order to quantify, in a theoretical way, through mathematical equations, the amount of biomass. In several plantations of EG, different variables of some trees were measured, with which the average values that are reflected in Table I were obtained.
These trees were cut and divided, decomposing the biomass in the following fractions:

- $\quad$ Wood (up to $7 \mathrm{~cm}$ in end with crust)

- Crust

- Big branches (diameter of the insertion in the trunk or a superior branch, between 7 and $2 \mathrm{~cm}$ )

- Medium branches (diameter of the insertion in the trunk or a superior branch, between 2 and $0.5 \mathrm{~cm})$

- Small branches (diameter of the insertion in the trunk or a superior branch, smaller than $0.5 \mathrm{~cm}$ )

- Leaves

The equations for the biomass estimation of the EG are, according to this study, those that are shown in Table II:

TABLE II.- Equations for the biomass estimation in EG plantations

\begin{tabular}{|l|l|l|}
\hline Fraction & Equation & $\mathrm{R}^{2}$ \\
\hline Wood & $\mathrm{W}=0,0062 \mathrm{~d}^{2,35} \mathrm{~h}^{1,001}$ & 0,97 \\
\hline Crust & $\mathrm{W}=0,0093 \mathrm{~d}^{2,46}$ & 0,71 \\
\hline Big branches & $\mathrm{W}=0,0076 \mathrm{~d}^{3,39} \mathrm{G}^{-0,83}$ & 0,70 \\
\hline Medium branches & $\mathrm{W}=0,00264 \mathrm{~d}^{2,63} \mathrm{G}^{-0,81}$ & 0,85 \\
\hline Small branches & $\mathrm{W}=0,0451 \mathrm{~d}^{3,08} \mathrm{G}^{-1,59}$ & 0,76 \\
\hline Leaves & $\mathrm{W}=0,0043 \mathrm{~d}^{3,69} \mathrm{G}^{-1,22}$ & 0,75 \\
\hline Brotes $(\mathrm{d}=5 \mathrm{~cm})$ & $\mathrm{W}=0,2536 \mathrm{~d}^{2,4579}$ & 0,99 \\
\hline
\end{tabular}

As the values of the attached tables reflect, the value of biomass oscillates between 142 and $426 \mathrm{Tn} / \mathrm{ha}$. These data correspond to the youngest plantations, and the oldest ones, respectively. The percentage in weight are practically constant, independently of the plantation age. From the tables it is deduced that the fraction of residual

TABLE III.- Amount of dry biomass in Tn/ha of the different EG components (\% of dry weight of each fraction)

\begin{tabular}{|c|c|c|c|c|c|c|c|}
\hline & Wood & Crust & $\begin{array}{c}\text { Big } \\
\text { branches }\end{array}$ & $\begin{array}{l}\text { Medium } \\
\text { branches }\end{array}$ & $\begin{array}{c}\text { Small } \\
\text { branches }\end{array}$ & Leaves & Total \\
\hline Average & $\begin{array}{c}184,7 \\
(82,3 \%) \\
\end{array}$ & $\begin{array}{c}16 \\
(7,4 \%) \\
\end{array}$ & $\begin{array}{c}11,5 \\
(5,4 \%) \\
\end{array}$ & $\begin{array}{c}4,2 \\
(2,1 \%) \\
\end{array}$ & $\begin{array}{c}1,8 \\
(0,9 \%) \\
\end{array}$ & $\begin{array}{c}4,1 \\
(2 \%) \\
\end{array}$ & 222,3 \\
\hline Typical desviation & $\begin{array}{c}92,7 \\
(2,2 \%)\end{array}$ & $\begin{array}{c}6 \\
(0,7 \%)\end{array}$ & $\begin{array}{c}4,4 \\
(1 \%)\end{array}$ & $\begin{array}{c}0,8 \\
(0,5 \%)\end{array}$ & $\begin{array}{c}0,4 \\
(0,4 \%)\end{array}$ & $\begin{array}{c}1,5 \\
(0,6 \%)\end{array}$ & 105 \\
\hline Maximum & $\begin{array}{c}364,7 \\
(85,5 \%) \\
\end{array}$ & $\begin{array}{c}27 \\
(6,3 \%) \\
\end{array}$ & $\begin{array}{c}20,1 \\
(4,7 \%)\end{array}$ & $\begin{array}{c}5,7 \\
(1,3 \%) \\
\end{array}$ & $\begin{array}{c}2,1 \\
(0,5 \%) \\
\end{array}$ & $\begin{array}{c}6,9 \\
(1,6 \%) \\
\end{array}$ & 426,6 \\
\hline Minimum & $\begin{array}{c}111,9 \\
(78,7 \%)\end{array}$ & $\begin{array}{c}10 \\
(7 \%)\end{array}$ & $\begin{array}{c}10,1 \\
(7,1 \%)\end{array}$ & $\begin{array}{c}3,8 \\
(2,7 \%)\end{array}$ & $\begin{array}{c}2,2 \\
(1,5 \%)\end{array}$ & $\begin{array}{c}4,2 \\
(3 \%)\end{array}$ & 142 \\
\hline
\end{tabular}


forest biomass (crust, branches, and leaves) is $20 \%$ of the total.

\section{Basic systems of forest biomass collection}

In this section, the most common methods of forest residues collection are analyzed, as well as the description of diverse equipment.

In order to optimize the collection process of wastes from the traditional forest industry, it is necessary to integrate a few previous phases. For this, three basic situations are analyzed, figure 5 .

- The first situation presents the residues randomly dispersed in the plantation. It corresponds to most common case, and is also the worse one, since the efficiency of the collection is quite low (for the EG, around 4 tonnes of green material per hour of work).

- The second situation is the one that presents the residues grouped in piles ready throughout the surface of the plantation.

- The last situation presents the residues grouped in piles next to the track, what makes the collection work easy for a forest tractor. If the tractor cost is $27 € / \mathrm{h}$, the collection cost will be $6.8 €$ per ton. In order to decrease the humidity degree of the wastes, it is an advisable method to cover the piles with a special paper that facilitates the loss of humidity.
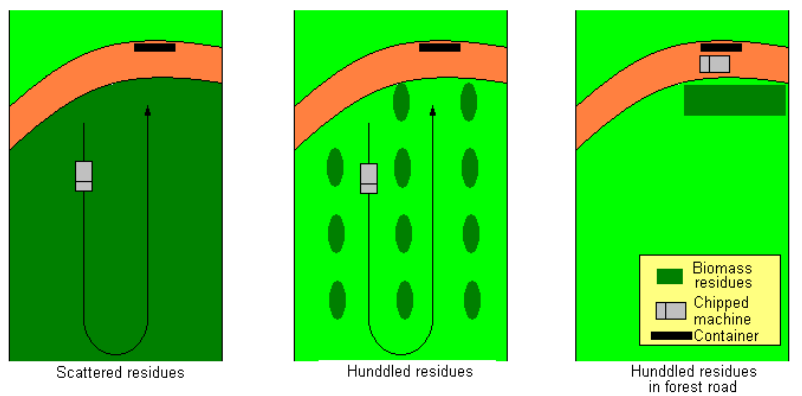

Fig 5.- Scheme of the three cases of residues collection

Due to the great dispersion of the biomass, the task that takes most of the time is the wastes collection with a crane, which means that the situations where the collection is already prepared show greater yields.

\subsection{Collection techniques of forestry industry wastes.}

In Europe diverse methods of forestry biomass collection have been used, mainly in Finland, Sweden, Germany and France. These are pioneering countries in the use of biomass for power production.

Due to the low apparent density of the wastes, the collection systems focus on increasing the density of the material.

Currently, two collection technologies exist:
- Chipped technique, that tries to reduce the wastes size.

- Compacted technique, that tries to compress the wastes.

\subsubsection{Equipment with chipped technology}

Its function is to divide in smaller pieces the biomass to facilitate the transport and storage.

Two types of chipped machines exist in the market and can be classified on the basis of their mobility.

- Movable chipped machines

- Semimovable chipped machines

Between the movable chipped machines, the Chipharvester, figure 6 , can be stood out. It has an independent engine of more than $400 \mathrm{CV}$. The biomass feeding is made through a table with motorized chains. The chipped element is a compression drum, with rollers connected to a chips storage container of $20 \mathrm{~m}^{3}$. The unloading is made turning the container. The set is installed on the chassis of a forest machine of high mobility, equipped with a self-loader (crane and clamp), figure 6 .

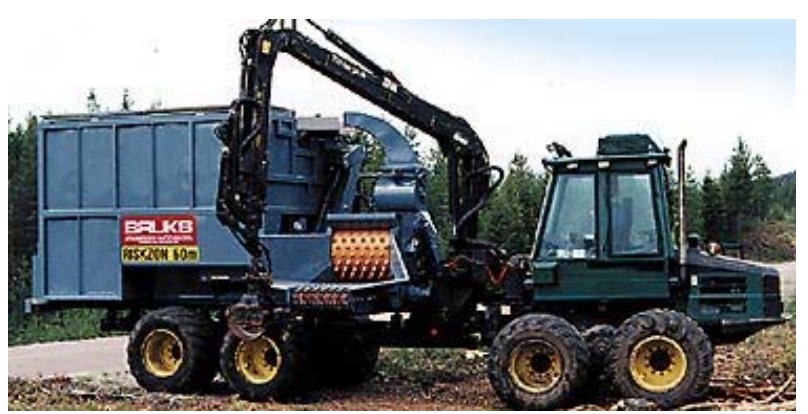

Fig 6.- Movable chipped machine

The work process consists of the following phases:

- $\quad$ Biomass feeding

- Chipped

- Transfering chips to the main container

- Unloading of chips on the container

- To gather the containers by conventional trucks

They are machines specially used in the Nordic countries, where they have been used for more than 20 years, reason why they accumulate great experience in operations with coniferous.

The production, when the biomass is grouped next to the track, can reach $60 \mathrm{~m}^{3}$ /hour. In situations with dispersed biomass, the production can descend to $38 \mathrm{~m}^{3} /$ hour.

A variable with great influence in the production, is the distance between the biomass collection point and the unloading point. In figure 7 , the production versus this distance has been represented. 


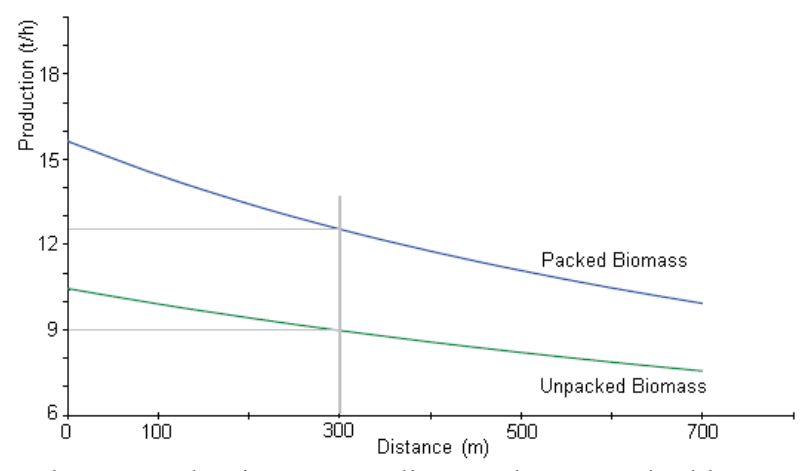

Fig 7.- Production versus distance between the biomass collection point and the unloading point

The density of the biomass chipped is around $320 \mathrm{~kg} / \mathrm{m}^{3}$, although the density obtained in the transport by highway usually is something greater, $385 \mathrm{~kg} / \mathrm{m}^{3}$, because the clamp of the crane compresses the material when loading it in the transport truck.

It is important to stand out that this equipment, in bad accessibility conditions, needs the support of a self-loader to make the transport from the chipped zone to the access tracks, where the containers are. This is a clear disadvantage of these machines, if they are compared with the compacted ones, in zones where the land has a considerable slope.

In the case of semimovable chipped machines, the Pezzolato model is quite common. The chipped equipment consists of a drum with blades installed on a rigid platform of two axis, being the forward one connected to the tractor to take traction of it.

The biomass feeding has to be make with a crane installed on an auxiliary vehicle. The entrance uses a table composed by a compression roller and a motorized belt. The containers have a capacity of $120 \mathrm{~m}^{3}$, and the unloading is made by means of an inclined transporter, located in the lateral part of the machine, figure 8 .

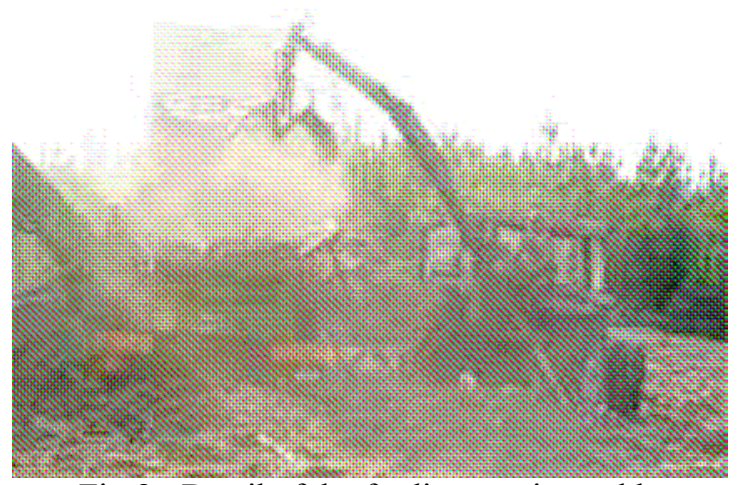

Fig 8.- Detail of the feeding semimovable chipped machine

The work process is the following one:

- $\quad$ Biomass feeding with the tractor

- Chipped

- Approach of the biomass with the tractor

- Chips unloading directly on truck

- To gather the containers by conventional trucks
The greatest disadvantage of this equipment is that it needs two auxiliary tractors for his feeding, and its zone of work must be accessible for trucks. So, it is only recommendable its use in the cases in which the accessibility is very good, and the biomass is in piles next to the track (approximate production around $30 \mathrm{~m}^{3} /$ hour).

\subsubsection{Equipment with compacted technology}

Its function is to make biomass packages, cutting them with the wished length. Mainly two types of compacted machines exist in the market:

Fiberpac, is a machine developed by the Finnish company Timberjack, specialists in machines for forestry works. The feeding is made by means of the clamp of the self-loader, that puts the biomass in an entrance table with a motorized roller.

It produces cylindrical packages of $70 \mathrm{~cm}$ of diameter and variable length, similar to the wood in roll machines, that ties with plastic cord. This allows to optimize the transport and storage, using conventional forest machines; in addition it do not need continuously the presence of containers.

The work process is the following one:

- $\quad$ Feeding of biomass remainders

- Compacted and tied of the remainders

- Court of the pack to the wished length

The machine production is limited by the cutting time of the package, since it represents an authentic bottleneck, with respect to the other tasks of the work cycle of the machine. At the moment the cutting systems are improving, and therefore reducing the cycle time, with the consequent increase of the machine productivity.

The main advantage of this machine is its high mobility. At the same time, the soil erosion caused by the wheels is relatively reduced.

Tests made in Catalonia and Galicia, demonstrate that the compacted machine Fiberpac, when it finds the biomass next to the track, the average production is around 18 biomass packages per hour. However; if the wastes are dispersed, the production descends to 13 packages per hour. The packages produced present a compacted degree independent of the humidity degree of the material.

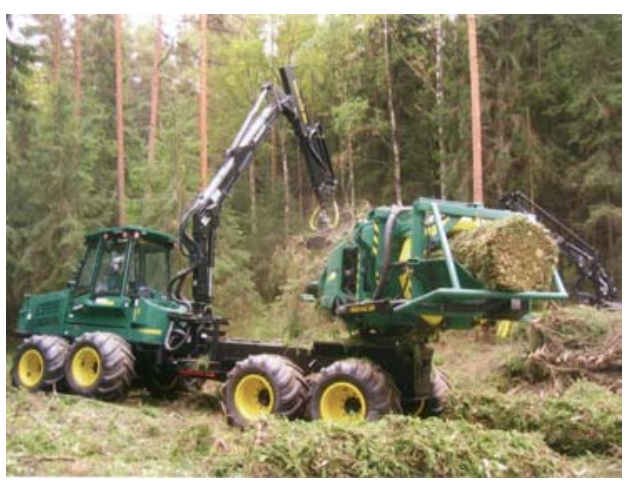

Fig 9.- Fiberpac 
The average weight of the packages, if the humidity is of $80 \%$ in dry base, is around $650 \mathrm{~kg}$, whereas if the humidity descends to values around $35 \%$, the weight is $480 \mathrm{~kg}$.

\subsection{Conclusions on the collection systems}

Analyzing the diverse methods of collection, it reaches the conclusion that the most adapted equipment for the characteristics of the north of Spain is the compacted Fiberpac. This is mainly based on two points:

- Great capacity to get in and to move in the forest tracks.

- The packages facilitates the pre drying of the residues; what is very important since the humidity degree has great influence in the power generated by the biomass.

\section{Environmental impact of the collections of the forest residues}

The wastes of cutting trees in a forest, as well as other components, perform functions that regulate, feed and protect the soil. Some of them are the following ones:

- $\quad$ Protection against the erosion (rain, wind...)

- After its decomposition they give back to the soil great part of the nutrients, since the branches are the parts that accumulate more nutrients.

- They increase in the soil the content of organic matter and carbon.

- They reduce to the water evaporation, preserving the humidity of the land.

- Thanks to the residues, machines and animals not compact the soil.

- They contribute to the regeneration of the forest.

The effects of the collection of the forest industry wastes, will be greater or smaller based on the quantity, the type of biomass, the species, the type of soil, the type of extraction system, etc.

Nowadays, diverse environmental aspects are been studied, between which it is possible to emphasize the following ones:

- Determination of the amount and distribution of nutrients in the different parts of the tree and in the soil, with the purpose of defining the nutritional stability of the system.

- Evaluation of the effect that has collecting wastes on the erosion of the soil.
- Surveillance of the natural regeneration and organic matter on the soil.

\section{Forest biomass like fuel for electricity generation}

Fuel is any substance that when reacts with oxygen produces heat. However, only those substances that generates a significant amount of heat are considered as fuels.

Regarding the combustion process, the following hypothesis are assumed:

- $\quad$ Humidity degree of the sample $0 \%$

- Excess of air in combustion 0\%

- Complete combustion, without CO production

- Ideal behavior of the resulting gases

$$
\begin{gathered}
\mathrm{E}_{\text {reac }}=\mathrm{E}_{\text {prod }} \\
\sum_{\text {reac }} \mathrm{n}_{\mathrm{r}}\left(\mathrm{h}_{\mathrm{f}}+\Delta \mathrm{h}_{\mathrm{f}}\right)_{\mathrm{r}}=\sum_{\text {prod }} \mathrm{n}_{\mathrm{p}}\left(\mathrm{h}_{\mathrm{f}}+\Delta \mathrm{h}_{\mathrm{f}}\right)_{\mathrm{p}}
\end{gathered}
$$

being $E$ energy

$n_{\mathrm{r}} \quad$ the number of mols of reactive

$n_{\mathrm{p}}$ the number of mols of product

$h_{\mathrm{f}}$ the entalpía de formación

$\Delta h_{\mathrm{f}}$ variación de la entalpía de formación

The ideal temperature of the flame is around $805^{\circ} \mathrm{C}$, but in real conditions it is less, since an excess of oxygen is needed, the humidity that the fuel has, etc. These points determine the type of installation to use. For example, gas turbines cannot be used, since to obtain acceptable yields, greater flame temperatures are required, around $1,150^{\circ} \mathrm{C}$.

If the forest biomass is used for the production of electrical energy in a conventional power station with steam turbine, the maximum temperature that could reach the steam in a boiler would not surpass $500^{\circ} \mathrm{C}$, which limits the yield of the power station to values around $30 \%$.

\section{Economic analysis}

The economic study deals with a conventional power station for generation of electrical energy, from the combustion of biomass residues of the forest industry (EG), produced in the province of Cantabria.

\subsection{Power potential}

According the Government of Cantabria, an average of $550,000 \mathrm{~m}^{3}$ of EG are cut per year. Considering a density of $785 \mathrm{~kg} / \mathrm{m}^{3}$ [10], which means $432,000 \mathrm{Tn}$ of useful wood $(20 \%$ of the tree are wastes); the result is that approximately $110,000 \mathrm{Tn}$ of wastes remain in the plantations every year. 
Considering that it was possible to gather only $50 \%$ of the wastes in the plantations, since a part of them are not easily accessible, the power station would have a primary energy of $1.08 \times 10^{12} \mathrm{~kJ}$.

If the average number of working hours per year of the power station is around the 6,500, and this has an electrical yield of $20 \%$, the electrical power to consider, with these conditions, is $8 \mathrm{MW}$.

Moreover, taking into account the data of several european power stations of biomass, it is possible to calculate that the cost of the power station is approximately 1 M€ per MW of the facility [11].

\subsection{Incomes from the electricity sale}

The TMR according to BOE is $0.072072 € / \mathrm{kWh}$. The sale price of the electricity generated from forest biomass is $90 \%$ of the TMR, which means a price of 0.06486 $€ / \mathrm{kWh}$.

If the facility power is $8 \mathrm{MW}$, and the annual use is 6,500 $\mathrm{h}$, the expected incomes will be greater than $3.4 \mathrm{M} €$.

\subsection{Operation costs}

The first investment is the purchase of the raw material, the wastes of the forest industry, which is considered around $0.0085 €$ per $\mathrm{kg}$.

The costs analysis for the biomass collecting is made for a Fiberpac machine. It has been considered a cost of 90 $€ /$ hour, and an average production of 14 packages per hour, or $6,720 \mathrm{~kg} / \mathrm{h}$, which represents a cost of 0.013 $€ / \mathrm{kg}$.

On the other hand, the transport of the packages to the power station, according to the truck drivers tariffs, is $0.024 € / \mathrm{kg}$.

This way, the price of the 55,000 Tn of biomass unloaded in the power station is, approximately $2.46 \mathrm{M} €$.

The operation and maintenance costs of the power station can represent $20 \%$ of the incomes for the electricity sale, therefore, they can reach $672,000 €$ per year.

\subsection{Yield}

Taking into account the previous costs, the annual benefit, defined as the difference between incomes and costs would be $940,000 €$.

Moreover, considering the investment made and an interest rate of $5 \%$, the result is that the investment is amortized in a period of time over 10 years. This explains why these projects are not attractive from a financial point of view, and why they are only interesting when public support exists.

\section{CONCLUSIONS}

The forest biomass is a fuel whose use presents several disadvantages, if it is compared to other fuels, as those derived from the petroleum. Among these problems, the following ones can be mentioned:

The location; the forest are in the nature, occupying great and dispersed land areas, that usually are not easily accessible. This causes that the work there is problematic, and therefore represents a high economic cost. This disadvantage does not exist in the case of the industrial forest biomass.

On the other hand, this biomass is little compact, therefore its density is very low and the volume that occupies in the transport and in the storage is elevated, which increases the prices of these processes.

In order to correct these effects, there are special machines to gather and crush, figure 6, or to compact, figure 9 , the wastes in the forest. The process chosen depends fundamentally on the place accessibility. However, even when the global costs are reduced with these machines, the price of taking the wastes to the load point in the forest, is elevated.

The impoverishment of the soil, as a result of the lack of awareness on its care. So, the nutricional balance in the plantations must be maintained, after that the forest wastes have been collected.

The biomass presents a low temperature of flame. This parameter depends on the chemical composition of the fuel. For the biomass it is a relatively low value and determines the type of technology that can be used in order to get a profitable facility.

The biomass is a native resource, therefore, its use contributes to eliminate the strong power dependency that Spain has with the petroleum and gas producers.

The use of the biomass as power source means to increase the value of the existing or possible resources of the rural areas. The countryside has traditionally a depressed economy and tends to become depopulated. Studies made in Germany show that the biomass energy creates between 3.3 and 5 times more jobs than the gas, or between 2.8 and 4.3 times more jobs than the petroleum [8].

In order to support the development of this type of energy the land should be cultivate with specific species. This is a significant environmental advantage contributing to reduce the greenhouse effect, since the plants and trees behave like $\mathrm{CO}_{2}$ drains.

From the economic point of view, the yield of the investments to make is low. Therefore, if the biomass energy it is wanted, its production and use should be appropriately subsidized, or the use of other energies should be penalize by means of the payment of a tax for the emission of the polluting agents that its use generates. 


\section{References}

[1] http://europa.eu.int/comm/eurostat/

[2] Energía de la Biomasa, Manuales de Energías Renovables, Ed IDAE, 1996

[3] P. Pozo DTIE 10.03, Calderas Individuales

[4] Gas, Cuadernos

[5] DTIE, Combustión 6.01, Aurelio Alamán

[6] M. J. Moran y H. N. Shapiro, Fundamentos de Termodinámica Técnica, Ed Reverté

[7] http://www.eere.energy.gov

[8] http://www.mediambient.gencat.net/cat/cpf/

[9] Real Decreto 436/2004

[10] http://www.uhu.es/cideu/

[11] Renewable Energy: Best Practice Projects Yearbook, Cap 2 Biomass, Energie

[12] http://webs.uvigo.es/csouto/ 